\title{
Oxidação Lipídica do Óleo de Vísceras de Aves para Redução de seu Conteúdo de Energia Metabolizável para Frangos de Corte na Fase de Crescimento ${ }^{1}$
}

\author{
Aline Mondini Calil Racanicci ${ }^{2}$, José Fernando Machado Menten ${ }^{3}$, Marisa Aparecida Bismara \\ Regitano-D’Arce ${ }^{4}$, Juliano Benedito Gaiotto ${ }^{5}$, Flávio Alves Longo ${ }^{6}$, Adriana Ayres Pedroso 7 , \\ José Otávio Berti Sorbara 8
}

\begin{abstract}
RESUMO - Com a finalidade de determinar os teores de energia metabolizável aparente (EMA) e de energia metabolizável aparente corrigida para o nitrogênio (EMAn) do óleo de vísceras de aves fresco e oxidado, foi conduzido um ensaio metabólico utilizando-se 48 machos AgRoss com 31 dias de idade. As aves foram alojadas em gaiolas metabólicas e o método utilizado foi o de coleta total de excretas. Foi fornecida uma dieta-referência com ou sem substituição de $10 \%$ pelo óleo de vísceras de aves fresco ou oxidado, sendo que cada dieta foi oferecida a quatro repetições de quatro aves. O período de coleta foi de quatro dias após três dias de adaptação às dietas e às gaiolas. O óleo de vísceras de aves foi adquirido de um produtor local e armazenado sob congelamento a $-18^{\circ} \mathrm{C}$ (óleo fresco). O óleo oxidado foi obtido por aquecimento em banho-maria com temperatura entre 80 e $90^{\circ} \mathrm{C}$. Durante o período de aquecimento, a qualidade deste óleo foi controlada por avaliações periódicas da absorbância específica, que indica o acúmulo de compostos de ranço. Os valores de absorbância específica, medidos a 232 e $270 \mathrm{~nm}$, foram, respectivamente, de 4,64 e 0,47 para o óleo fresco e de 18,54 e 3,76 para o óleo oxidado. Os resultados obtidos, expressos na matéria original, para EMA e EMAn foram de 9.240 e $9.150 \mathrm{kcal} / \mathrm{kg}$ para o óleo de vísceras fresco e 7.700 e $7.595 \mathrm{kcal} / \mathrm{kg}$ para o óleo oxidado, comprovando estatisticamente grande redução no conteúdo de energia metabolizável do óleo decorrente do processo oxidativo.
\end{abstract}

Palavras-chave: energia, ensaio de metabolismo, frangos de corte, gordura oxidada, oxidação lipídica, peroxidação

\section{Lipid Oxidation Decreases Metabolizable Energy Value of Dietary Poultry Fat for Growing Broilers}

\begin{abstract}
In order to determine the apparent metabolizable energy (AME) and N-corrected apparent metabolizable energy (AMEn) of fresh and oxidized poultry fat a metabolism assay with 48 AgRoss male broilers from 31 to 34 days of age was conducted. The birds were fed a basal diet or this diet replaced by $10 \%$ of fresh or oxidized fat and the total excreta collection method was applied. The birds were housed in metabolic cages and each diet was supplied for four replicates of four birds. Fresh poultry fat was supplied by a local rendering and then stored frozen $\left(-18^{\circ} \mathrm{C}\right)$. The oxidized poultry fat was obtained by heating $\left(80-90^{\circ} \mathrm{C}\right)$ and specific absorbances were measured frequently to control fat quality. Specific absorbances at 232 and $270 \mathrm{~nm}$ were, respectively, 4.64 and $0.47 \mathrm{for}$ fresh fat and 18.54 and 3.76 for oxidized fat, which suggest higher levels of conjugated dienes in the oxidized poultry fat. The results of AME and AMEn were 9,240 and 9,150 kcal/kg (as fed-basis) for the fresh poultry fat and 7,770 and 7,595 kcal/kg (as fed-basis) for the oxidized poultry fat. AME and AMEn values were statistically different, indicating a decrease in the energy from the fresh poultry fat to the oxidized fat due to oxidation.
\end{abstract}

Key Words: broilers, energy, oxidized fat, peroxidation, lipid oxidation, metabolism assay

\section{Introdução}

Óleos e gorduras são ingredientes muito utilizados nas rações como fonte concentrada de energia, permitindo a formulação de dietas de alta energia para frangos de corte. A indústria avícola tem utilizado em larga escala subprodutos de abatedouros adicionados às rações, como o óleo de vísceras de aves, que tem como principal vantagem o baixo custo e o alto conteúdo energético $(9.360 \mathrm{kcal} / \mathrm{kg}$, de acordo com o NRC, 1994). No entanto, o perfil de ácidos graxos deste óleo favorece o desenvolvimento da rancidez

\footnotetext{
${ }^{1}$ Parte da tese de doutorado do primeiro autor. Pesquisa financiada pela FAPESP.

2 Aluna de Doutorado do Dep. Zootecnia da ESALQ/USP, Piracicaba/SP. Bolsista FAPESP. E-mail: amcracan@esalq.usp.br

3 Orientador e Professor do Dep. Zootecnia da ESALQ/USP, Piracicaba/SP. E.mail: jfmmente@esalq.usp.br

4 Co-orientadora e Professora do Dep. Agroindústria, Alimentos e Nutrição da ESALQ/USP, Piracicaba/SP. E.mail: mabra@esalq.usp.br

5 Aluno de doutorado do Dep. Zootecnia da ESALQ/USP, Piracicaba/SP. Bolsista da FAPESP. E.mail: jgaiotto@yahoo.com.br

${ }^{6}$ Aluno de doutorado do Dep. Zootecnia da ESALQ/USP, Piracicaba/SP. Bolsista da FAPESP. E.mail: falongo@yahoo.com

7 Aluna de doutorado do Dep. Zootecnia da ESALQ/USP, Piracicaba/SP. Bolsista da FAPESP. E.mail: adrianap@esalq.usp.br

8 Aluno de mestrado do Dep. Zootecnia da ESALQ/USP, Piracicaba/SP. Bolsista da FAPESP. E.mail: jobsorbara@hotmail.com
} 
oxidativa devido à grande quantidade de ácidos graxos insaturados, principalmente os ácidos oléico (C18:1) e linoléico (C18:2).

Os ácidos graxos insaturados são facilmente oxidados, em virtude da presença de duplas ligações nas cadeias de carbono de sua estrutura química (Robey \& Shermer, 1994). De acordo com o NRC (1994), os ácidos oléico e linoléico representam, juntos, 69,50\% do total de gordura deste óleo.

Segundo Scott (1982), o processo de oxidação lipídica é a principal causa da perda de qualidade do alimento ou da ração, afetando seu sabor, aroma, cor e textura, além de resultar na produção de compostos tóxicos e em sério decréscimo de seu valor nutritivo.

Os efeitos no desempenho, pelo ganho de peso, consumo de ração ou pela conversão alimentar, identificados em estudos com aves submetidas a estresse oxidativo (Cabel et al., 1988; Engberg et al., 1996) decorrem, provavelmente, da redução do conteúdo energético do óleo, da presença de compostos de ranço e da baixa eficiência da utilização deste alimento pelos animais.

O principal objetivo deste estudo foi quantificar a redução da EMA e EMAn do óleo de vísceras de aves, em conseqüência de sua oxidação, e gerar informações sobre a real suscetibilidade desta matéria-prima à oxidação e à utilização de metodologias de análise para o acompanhamento de sua qualidade durante o processo oxidativo.

\section{Material e Métodos}

O ensaio experimental foi realizado nas instalações do Departamento de Zootecnia da Escola Superior de Agricultura “Luiz de Queiroz”, em Piracicaba, SP. O processo de oxidação do óleo de vísceras de aves e as análises de acompanhamento da qualidade do óleo foram conduzidos no Laboratório de Óleos e Gorduras do Departamento de Agroindústria, Alimentos e Nutrição da mesma escola.

O óleo de vísceras de aves foi adquirido de um fornecedor regional e mantido congelado $\left(-18^{\circ} \mathrm{C}\right)$ desde sua extração até sua mistura nas rações. Este tratamento foi denominado óleo fresco. O óleo de vísceras oxidado foi obtido por aquecimento intermitente com temperatura em torno de 80 a $90^{\circ} \mathrm{C}$ em banho-maria, com constante aeração por um período de 40 dias.

Diariamente, durante todo o processo de oxidação do óleo, foram coletadas amostras para acompa- nhamento da oxidação. Nestas amostras, foram feitas determinações de Índice de Peróxidos conforme metodologia descrita no COMPÊNDIO (1998). Entretanto, este método mostrou-se pouco eficiente para o acompanhamento da oxidação do óleo por período prolongado. Por este motivo, foram quantificados também os produtos da oxidação (dienos e trienos) pelo método espectrofotométrico IUPAC número II.D.23 (1979), que permite determinar a absorbância do óleo em determinados comprimentos de onda do espectro ultravioleta e fornece indicação de seu grau de oxidação. Isto porque os produtos da oxidação (dienos conjugados em $232 \mathrm{~nm}$ e trienos conjugados ou compostos secundários em $270 \mathrm{~nm}$ ) se apresentam em espectros característicos na região ultravioleta. Geralmente, a determinação da absortividade a $232 \mathrm{~nm}$ e a $270 \mathrm{~nm}$ pode fornecer indicativo do estado de oxidação do óleo, revelando da presença de seus compostos secundários (White, 1995).

Na fase que antecedeu o ensaio de metabolismo, os animais foram criados de forma convencional em piso com cama e alimentados à vontade com ração à base de milho e farelo de soja com $3.050 \mathrm{kcal} / \mathrm{kg}$ de energia e $21,5 \%$ de proteína bruta.

Aos 28 dias de idade, 48 animais foram transferidos para uma sala climatizada contendo uma bateria de 12 gaiolas metabólicas, marca Petersime. Cada gaiola, com 0,70 m de comprimento por 0,66 m de largura e $0,34 \mathrm{~m}$ de altura, abrigou quatro aves com peso médio de $1,2 \mathrm{~kg}$ recebendo ração e água à vontade. O período de adaptação às gaiolas e à dieta foi de três dias antecedetes aos quatro dias de coleta das excretas. $\mathrm{O}$ início e o final do período de coleta foram definidos pelo fornecimento de ração marcada com óxido de ferro e aparecimento das excretas pigmentadas.

Utilizou-se uma ração-referência isenta de óleo suplementar (Tabela 1) formulada à base de milho e farelo de soja de acordo com as exigências das aves na fase de crescimento (Rostagno, 2000), e duas rações-teste obtidas pela substituição da ração-referência por $10 \%$ do óleo de vísceras de aves fresco ou oxidado, que representaram os dois tratamentos estudados. O preparo das rações experimentais foi feito imediatamente antes do início do experimento e as rações foram mantidas em sala climatizada com temperatura média entre 25 e $28^{\circ} \mathrm{C}$, juntamente com as aves.

O período de coleta de excretas foi de 31 a 34 dias de idade das aves, sendo a coleta efetuada duas vezes ao dia. No momento da coleta, tomou-se o devido cuidado em recolher toda a excreta eliminada no

\footnotetext{
R. Bras. Zootec., v.33, n.4, p.919-923, 2004
} 
período, evitando-se o excesso de contaminação com penas ou ração.

As amostras foram armazenadas em congelador apropriado até o momento da pesagem, quando foram descongeladas e homogeneizadas. Foi retirada uma amostra representativa de cada repetição para présecagem, que foi feita em estufa de circulação forçada a $65^{\circ} \mathrm{C}$ por 72 horas. Em seguida, as amostras representativas foram moídas para determinação de umidade total, nitrogênio, extrato etéreo e proteína bruta. As análises de rações e excretas foram realizadas em laboratório particular (CBO Assessoria \& Análise, em Campinas/SP).

As determinações de energia bruta das rações e das excretas foram feitas no Laboratório de Bromatologia do Departamento de Zootecnia utilizando-se a bomba calorimétrica Parr modelo 1261 e a metodologia de Matterson et al. (1965) para o cálculo da EMA e EMAn.

Os valores de EMA e EMAn médios para os dois tratamentos (óleo fresco e óleo oxidado) foram comparados pelo teste t do Sistema SAS (1989).

\section{Resultados e Discussão}

Os resultados das análises dos óleos de vísceras de aves fresco e oxidado estão apresentados nas Tabelas 2 e 3. Os teores de umidade, acidez e índice de peróxidos foram mais elevados para o óleo oxidado, entretanto, os valores de absortividade, indicativos da presença de compostos de oxidação é que efetivamente caracterizam o estado oxidativo do ingrediente. $\mathrm{O}$ óleo de vísceras fresco apresentou valores baixos (4,64 e 0,47 em 232 e $270 \mathrm{~nm}$, respectivamente), indicando pequena quantidade de compostos primários e secundários de ranço, enquanto no óleo oxidado as absortividades foram bem mais elevadas (18,54 e 3,76 em 232 e $270 \mathrm{~nm}$, respectivamente), o que revela estado oxidativo adiantado.

Informações também interessantes foram fornecidas pela análise do perfil dos ácidos graxos presentes nos óleos utilizados neste estudo. Como pode-se verificar na Tabela 3, houve alteração no perfil das amostras analisadas após a oxidação. De maneira geral, houve ligeiro aumento nos teores dos ácidos graxos, exceto os ácidos linoléico (C18:2) e linolênico (C18:3), que apresentaram acentuadas reduções no óleo oxidado. Estas reduções são resultantes de sua degradação durante o processo oxidativo a que o óleo foi submetido e geraram os
Tabela 1 - Composição percentual da ração-referência e níveis calculados dos nutrientes

Table 1 - Composition of the reference diet and calculated nutrients

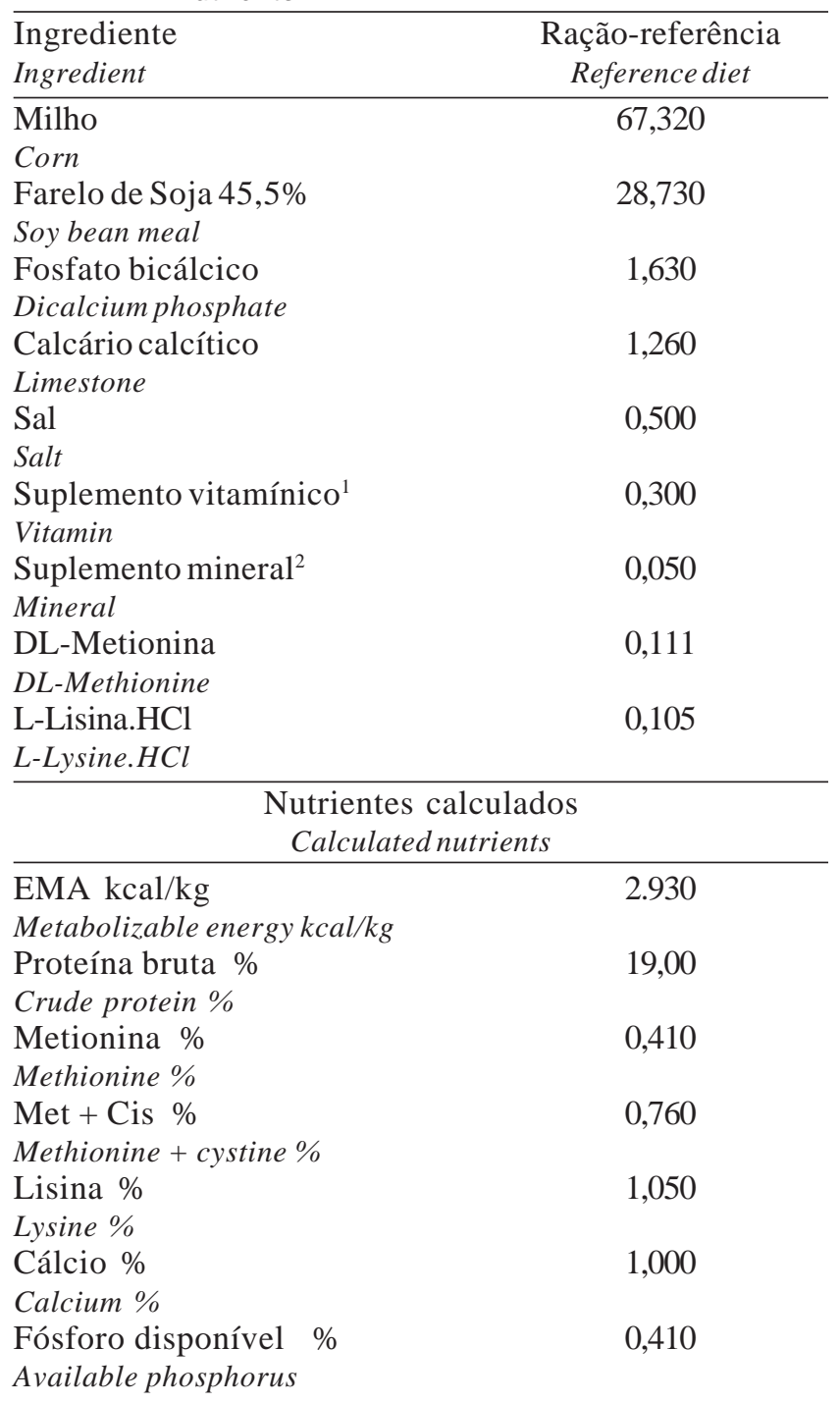

${ }^{1}$ Suplementação por $\mathrm{kg}$ de ração (supplying per $\mathrm{kg}$ of diet): ácido fólico (folic acid), 0,999 mg; ácido pantotênico (pantothenic acid), 15,00 mg; BHT, 22,5 mg; biotina (biotin), 0,06 mg; colina (choline), $39 \mathrm{mg}$; niacina (niacin), $40 \mathrm{mg}$; selênio (selenium), 0,3 mg; vit. A, 7.998,00 UI; vit. $D_{3} 1,998 \mathrm{UI}$; vit. E, $15 \mathrm{Ul}$; vit. K, 1,8 mg; tiamina (thiamin), 1,8 mg; riboflavina (riboflavin), 6,0 mg; vit. $\mathrm{B}_{6}, 2,8 \mathrm{mg}$; vit. $\mathrm{B}_{12}, 12 \mathrm{mg}$; olaquindox, $40 \mathrm{mg}$; avilamicina (avilamycin), $5 \mathrm{mg}$; salinomicina (salmomycin), $66 \mathrm{mg}$; ácido 3-nitro (3-nitro acid), $35 \mathrm{mg}$.

2 Suplementação por kg de ração (supplying per $\mathrm{kg}$ of diet): manganês (manganese), $75 \mathrm{mg}$; zinco (zinc), $50 \mathrm{mg}$; ferro (iron), $50 \mathrm{mg}$; cobre (copper), $8 \mathrm{mg}$; iodo (iodine), 0,75 mg.

compostos dienos e trienos encontrados na análise da absortividade. Semelhantes alterações no perfil de ácidos graxos foram encontradas por Sheehy et al. (1994) e Engberg et al. (1996), quando promoveram a oxidação em óleos vegetais.

Na Tabela 4, encontram-se os resultados obtidos no ensaio metabólico para EMA e EMAn referentes ao óleo fresco e ao oxidado. Os teores de EMA e 
EMAn encontrados para o óleo fresco (9.240 e 9.150 $\mathrm{kcal} / \mathrm{kg}$ ) estão em conformidade com os $9.360 \mathrm{kcal} / \mathrm{kg}$ apresentados pelo NRC (1994), assim como a composição do óleo em ácidos graxos.

Já a comparação dos resultados de EMA e EMAn para o óleo oxidado, torna-se muito difícil, em razão da escassez de resultados publicados. Pode-se afirmar, contudo, que houve efeito acentuado do estado oxidativo do óleo de vísceras de aves sobre os teores de energia obtidos, refletindo redução de cerca de 17\% nos valores de EMA e EMAn do óleo oxidado em relação ao mesmo ingrediente mantido fresco.
Alguns autores afirmam que os efeitos negativos do óleo oxidado fornecido na dieta se devem à sua menor palatabilidade e, conseqüentemente, ao menor consumo por parte dos animais. Contudo, apesar da alta inclusão de óleo nas rações-teste deste estudo, não foi verificada redução no consumo de ração do tratamento com óleo oxidado (460 g/ave) em relação ao óleo fresco (455 g/ave) nos quatro dias do ensaio.

Por outro lado, de acordo com Engberg et al. (1996), dependendo da origem do óleo e das condições a que foi submetido, durante a oxidação (temperatura e duração do aquecimento, adição de oxigênio

Tabela 2 - Características do óleo de vísceras fresco e oxidado Table 2 - Characteristics of fresh and oxidized poultry fat

\begin{tabular}{|c|c|c|c|}
\hline $\begin{array}{l}\text { Análises } \\
\text { Analysis }\end{array}$ & $\begin{array}{l}\text { Unidades } \\
\text { Units }\end{array}$ & $\begin{array}{c}\text { Óleo fresco } \\
\text { Fresh poultry fat }\end{array}$ & $\begin{array}{c}\text { Óleo oxidado } \\
\text { Oxidized poultry fat }\end{array}$ \\
\hline $\begin{array}{l}\text { Umidade }^{1} \\
\text { Moisture }^{1}\end{array}$ & $\%$ & 0,04 & 0,27 \\
\hline $\begin{array}{l}\text { Acidez }^{1} \\
\text { Acidity }^{1}\end{array}$ & $\mathrm{mg} \mathrm{KOH} / \mathrm{g}$ & 1,49 & 4,24 \\
\hline $\begin{array}{l}\text { Extrato etéreo }^{1} \\
\text { Ether extract }^{1}\end{array}$ & $\%$ & 99,51 & 99,85 \\
\hline $\begin{array}{l}\text { Índice de peróxidos }{ }^{1} \\
\text { Peroxide value }^{1} \\
\text { Absortividade } \\
\text { Specific absorbance }\end{array}$ & $\begin{array}{c}\mathrm{meq} / \mathrm{kg} \\
\mathrm{meq} / \mathrm{kg}\end{array}$ & 0,78 & 4,17 \\
\hline $\begin{array}{l}232 \mathrm{~nm} \\
270 \mathrm{~nm}\end{array}$ & & $\begin{array}{l}4,64 \\
0,47\end{array}$ & $\begin{array}{c}18,54 \\
3,76\end{array}$ \\
\hline
\end{tabular}

${ }^{1}$ Análises realizadas no Laboratório CBO Assessoria \& Análise, Campinas/SP

${ }^{1}$ Analysis were performed at CBO Assessoria \& Análise, Campinas/SP

Tabela 3 - Perfil de ácidos graxos do óleo de vísceras de aves fresco e oxidado Table 3 - Fatty acid profile of fresh and oxidized poultry fat

\begin{tabular}{ccc}
\hline Ácidos graxos $(\%)^{1}$ & $\begin{array}{c}\text { Óleo fresco } \\
\text { Fresh poultry fat }\end{array}$ & $\begin{array}{c}\text { Óleo oxidado } \\
\text { Oxidized poultry fat }\end{array}$ \\
\hline C14:0 & 0,67 & 0,83 \\
C16:0 & 22,35 & 25,25 \\
C16:1 & 8,95 & 9,83 \\
C18:0 & 5,17 & 5,56 \\
C18:1 & 43,73 & 45,93 \\
C18:2 & 17,33 & 12,61 \\
C18:3 & 0,90 & - \\
C20:4 & 0,41 & - \\
C20:1 & 0,52 & - \\
Total AG Saturados & 28,60 & 31,64 \\
Total Saturated Fatty Acids & 71,43 & 68,37 \\
Total AG Insaturados & & \\
Total Unsaturated Fatty Acids & & \\
${ }^{1}$ Análises realizadas no Laboratório de Óleos e Gorduras da FEA - UNICAMP, Campinas/ \\
SP, em Cromatógrafo Gasoso Capilar - Perkin Elmer 8420. Método AOCS Ce 2-66 - com \\
BF ${ }_{3}$ (Analysis were performed at Fats and Oils Laboratory (FEA - UNICAMP) in Campinas/SP, using GC \\
equipment - Perkin Elmer 8420, method AOCS Ce 2-66 with BF ${ }_{3}$
\end{tabular}

R. Bras. Zootec., v.33, n.4, p.919-923, 2004 
Tabela 4 - Resultados médios de Energia Metabolizável Aparente (EMA) e corrigida para o Nitrogênio (EMAn) para o óleo de vísceras de aves fresco e oxidado (valores expressos na matéria seca)

Table 4 - Means of apparent metabolizable energy (AME) and $N$-corrected metabolizable energy $\left(A M E_{n}\right)$ for fresh and oxidized poultry fat (based on dry matter)

\begin{tabular}{lcc}
\hline $\begin{array}{l}\text { Ingrediente } \\
\text { Ingredient }\end{array}$ & $\begin{array}{c}\text { EMA } \\
\text { AME }\end{array}$ & $\begin{array}{c}\text { EMAn } \\
A M E_{n}\end{array}$ \\
\cline { 2 - 3 } $\begin{array}{l}\text { Óleo fresco } \\
\text { Fresh poultry fat }\end{array}$ & \multicolumn{2}{c}{$(\mathrm{kcal} / \mathrm{kg})$} \\
$\begin{array}{l}\text { Óleo oxidado } \\
\text { Oxidized poultry fat }\end{array}$ & $7.770^{\mathrm{a}} \pm 317$ & $9.150^{\mathrm{a}} \pm 278$ \\
\hline
\end{tabular}

a,b Médias com letras diferentes na mesma coluna são diferentes $(P<0,0001)$ pelo teste $t$.

$a, b$ Means in the same column with no common superscript differ $(P<.0001)$ using $t$ test.

e catalisadores, e atividade de água), pode ser formada grande variedade de compostos de ranço quimicamente diferentes. Acredita-se que muitos destes compostos apresentem efeitos tóxicos ao organismo, provocando danos às células epiteliais do intestino e ao fígado, prejudicando a absorção e o aproveitamento do óleo oxidado. Talvez a presença de grande quantidade destes compostos de ranço no óleo oxidado (Tabela 2) seja essa a principal causa da redução dos valores energéticos obtidos neste ensaio.

Os efeitos negativos do fornecimento do óleo oxidado na dieta sobre o desempenho de frangos de corte já foram muitas vezes demonstrados (Lin et al., 1989) e acredita-se que a redução do crescimento pode ser atribuída à presença dos produtos da oxidação, que levam a valores reduzidos de energia da dieta pelo decréscimo do valor biológico do ingrediente oxidado. Os resultados deste estudo confirmam este fato e estão de acordo com Engberg et al. (1996), uma vez que os valores de EMA e EMAn são significativamente inferiores $(\mathrm{P}<0,0001)$ para o óleo de vísceras de aves submetido à oxidação.

\section{Conclusões}

O processo de oxidação lipídica provocou profundas alterações no óleo de vísceras de aves, que refletiram no valor biológico do óleo oxidado quando fornecido a frangos de corte na fase de crescimento.

\section{Agradecimento}

À Fundação de Amparo à Pesquisa (FAPESP), pelo financiamento e apoio ao desenvolvimento deste estudo.

\section{Literatura Citada}

AMERICAN OIL CHEMIST'S SOCIETY - AOCS. Official and tentative methods. Method AOCS Ce 2-66. Champaign: 1990.

CABEL, M.C.; WALDROUP, P.W.; SHERMER, W. et al. Effects of ethoxyquim feed preservative and peroxide level on broiler performance. Poultry Science, v.67, p.1725-1730, 1988.

COMPÊNDIO brasileiro de nutrição animal. Brasília: Ministério da Agricultura, 1998. $1 \mathrm{v}$.

ENGBERG, R.M.; LAURIDSEN, C.; JENSEN, S.K. et al. Inclusion of oxidised vegetable oil in broiler diets. Its influence on nutrient balance and on antioxidative status of broilers. Poultry Science, v.75, p.1003-1011, 1996.

INTERNATIONAL UNION OF PURE AND APPLIED CHEMISTRY (IUPAC). Standard methods for analysis of oils, fat and derivates. 6.ed. Thiais: $1979.2 \mathrm{v}$.

LIN, C.F.; ASGHAR, A.; GRAY, J.I. et al. Effects of oxidized dietary oil and antioxidant supplementation on broiler growth and meat stability. British Poultry Science, v.30, p.855-864, 1989.

MATTERSON, L.D.; POTTER, L.M.; STUTZ, N. et al. The metabolizable energy of feed ingredients for chickens. Research Report n. 7 - University of Connecticut, Agriculture Experimental Station, v.7, p. 3-11, 1965.

NATIONAL RESEARCH COUNCIL - NRC. Nutrient requirements of poultry. 9.ed. Washington, D.C.: National Academy Press, 1994. 71p.

ROBEY, W.; SHERMER, W. The damaging effects of oxidation. Feed Mix, v.2, n.5, p.22-26, 1994.

ROSTAGNO, H.S. Tabelas Brasileiras para aves e suínos. Composição de alimentos e exigências nutricionais. Viçosa, MG: Universidade Federal de Viçosa, 2000. 141p.

STATISTICAL ANALYSES SYSTEM - SAS. User's guide: statistics. Version 6. 4.ed. Cary: 1989.

SCOTT, M.L.; NESHEIN, M.C.; YOUNG, R.J. Nutrition of the chicken. 3.ed. Ithaca: M. L. Scott \& Associates, 1982. 562p.

SHEEHY, P.J.A.; MORRISSEY, P.A.; FLYNN, A. Consumption of thermally oxidized sunflower oil by chicks reduces $\alpha$ tocopherol status and increases susceptibility of tissues to lipid oxidation. British Journal of Nutrition, v.71, p.53-65, 1994.

WHITE, P. Conjugated diene, anisidine value, and carbonyl value analyses. In: WARNER, K.; ESKIN, M. (Eds.) Methods to assess quality and stability of oils and fat-containing foods. Champaign: AOCS Press, 1995. p.159-178.

Recebido em: 23/04/03 Aceito em: 03/09/03 